\title{
The Evaluation and Application of University WeChat Public Platform
}

\author{
Ruixian Fang ${ }^{1, a, *}$, Tongyu Ran ${ }^{1, b}$, Fen Liu ${ }^{1, c}$ \\ ${ }^{1}$ Xiamen University of Technology,Xiamen, Fujian,361024 \\ aRxfang@xmut.edu.cn, b455765442@qq.com, cLiufen@xmut.edu.cn
}

\begin{abstract}
Key Words: Colleges and universities, WeChat public platform, evaluation, AHP
Abstract. As the product of the transformation of university service under the new media environment, the university WeChat official account has become a new interactive public platform for university and university students, and its construction and evaluation help to improve the management of universities. Based on that, the Evaluation Index System of University WeChat Public Platform is constructed, the index weight is determined by AHP, and the Evaluation Model of University WeChat Public Platform is established. In this study, the Xiamen University of Technology WeChat Public Platform serves as an example for the evaluation, which provides suggestions and guidance for the construction and improvement of WeChat public platforms in colleges and universities.
\end{abstract}

\section{Introduction}

With the advent of the new media era, the rapid development of Internet technology has brought numerous opportunities for WeChat that focuses on the mobile platform. Currently WeChat has become the most influential communication mode of new media. According to Tencent Penguin Think Tank's 2017 WeChat Users \& Ecosystem Study Report, by December 2016, the company had had 889 million active users worldwide, compared with 10 million new WeChat official accounts. Since the launch of WeChat public platform, colleges and universities all over the country have seized the opportunity to set up the official accounts of WeChat, which have gradually become an important information platform for university administrators to spread the educational philosophy and campus culture to students. According to China's New Media Index System, 2,156 colleges and universities in China have applied for the WeChat official accounts, regularly publishing campus information [1]. The 2016 Blue Paper on New Media for Colleges and Universities released by the Hand University shows that the number of campus WeChat official accounts reached 80,000 in 2016, covering 33.98 million college students. Compared with new media such as microblogs, headlines and live streaming, the coverage rate of WeChat official accounts reached up to 92.93\%, the first among all kinds of new media. Therefore, the WeChat official account has become the most important platform for new media applications in colleges and universities.

More and more colleges and universities are becoming aware of the importance of the operation of WeChat public platform in their management, but these platforms are of varying quality. How to evaluate the operation of the public platforms? What problems exist during the process of construction? How to improve and perfect them? - All of these are still to be solved in the operation and management of new media in colleges and universities. Therefore, it is of great significance to construct the Evaluation Index System of University WeChat Public Platform and to use scientific methods to evaluate it. The literature review suggests that the research of WeChat public platforms in universities began in 2013, which mainly focused on the status quo, improvement countermeasures, spreading characteristics and their effects. However, few attention has been paid to how to evaluate the operation of the WeChat public platform. This paper designs the Evaluation Index System of University's WeChat Public Platform, uses the Analytic Hierarchy Process (AHP) to determine the index weight, and establishes the Evaluation Model of University WeChat Public Platform. In this research, the Xiamen University of Technology Wechat Public Platform provides an example for the empirical research of the application of this model.

\section{Evaluation Index System of University WeChat Public Platform}

In recent years, scholars at home and abroad have tried to evaluate the construction of multimedia 
information platform and the quality of service from various dimensions. For example, AI-Khalifa has developed a framework for evaluating mobile websites in colleges and universities that includes four dimensions: interface, navigation, content and service [2]. Lu and Lei put forward that the quality of network information service should be evaluated from six aspects: usefulness, usability, realization, tangibility, responsiveness and credibility [3]. On the basis of information content, accessibility, security, transference and usability, Guo has constructed the Service Quality Rating System of Government Affairs Public Platform [4]. In this study, the Evaluation Index System of University WeChat Official Account is based on the principles of comprehensibility, accessibility and easy to operate, etc, with reference to the existing evaluation system and expert interview. This system mainly includes four Level 1 Indexes: Platform Design, Platform Function, Platform Content, and Others. In Platform Design, there are three indexes: Friendliness, Simplicity and Aesthetics; Three indexes are set under Platform Function: Consultation and Interaction, Self-service Information and Notification Push; Platform Content includes five indexes: Richness, Timeliness, Practicality, Authority, and Personalization; and Others section has three indexes: Security, Accessibility, and Feedback. The above is shown in Table 1.

\section{AHP-based Evaluation Model of University WeChat Public Platform}

This paper uses the Analytic Hierarchy Process to construct the Evaluation Model of University WeChat Public Platform. Professor Thomas L. Saaty of the University of Pittsburgh in the US proposed a practical, multi-criteria decision-making approach in the early 1970s - Analytic Hierarchy Process, which can express a complex decision-making problem with an orderly hierarchical structure, and then give the order of alternatives after scientific calculation as well as in combination with people's subjective judgment. Thanks to the clear Analytic Hierarchy Process, the empirical judgment and reasoning of the decision makers can be linked and quantified, thus improving the efficiency and feasibility of decision-making. Therefore, it has been widely used in the comprehensive assessment, strategic planning, target analysis and scheme screening and so on [5]. The basic principle of Analytic Hierarchy Process is to divide the problem into several levels first, the above-level elements being the criterion, make pair judgments of the elements of the same level and compare their importance. Then the weights of the elements are calculated on the basis of the judgment results, and the optimal scheme can be

Table 1. The Evaluation Index System of University WeChat Public Platform

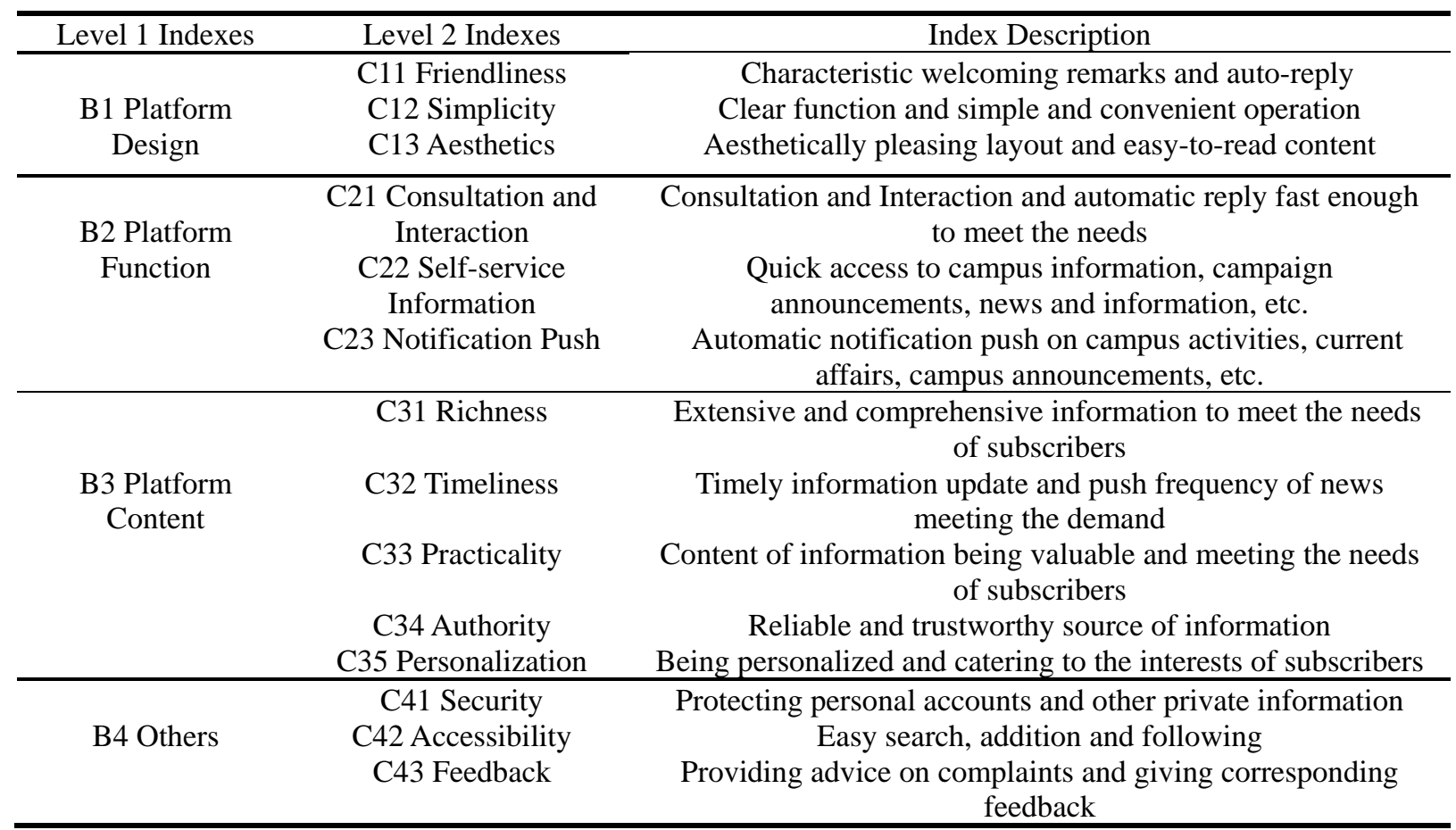


finally obtained by analyzing the combination weight according to the Principle of Maximum Weight. The main steps are as follows:

(1) Construct the Hierarchical Judgment Matrix. Pair comparisons are made for the same-level indexes, and the Judgment Matrix A is constructed after the scale values are determined according to the their relative importance.

(2) Single sorting and consistency tests at all levels.

a. Calculate the geometric means of all elements in each row of the Judgment Matrix: $\beta_{i}=\sqrt[n]{\prod_{j=1}^{n} a_{i j}}, \quad \mathrm{i}=1,2, \ldots \ldots \mathrm{n} ;$

b. Normalize the geometric means: $W_{i}=\frac{\beta_{i}}{\sum_{i=1}^{n} \beta_{i}} \quad, \mathrm{i}=1,2, \cdots \cdots \mathrm{n}$;

c. Get the maximum eigenvalue: $\lambda_{\max }=\frac{1}{n} \times \sum_{i=1}^{n} \frac{(A W)_{i}}{W_{i}}$;

d. Consistency test. Calculate the Consistency Index CI:

$$
C I=\frac{\lambda_{\max }-\mathrm{n}}{n-1} \text {. For convenience }
$$

sake, the Consistency Evaluation Index CR is introduced: $C R=\frac{C I}{R I}$. If CR is less than 0.1 , the Judgment Matrix is considered to be satisfactory and acceptable; otherwise it needs to be adjusted until it passes the consistency test. The values corresponding to the Random Consistency Index RI are shown in Table 2:

Table 2. Mean Random Consistency Index

\begin{tabular}{cllllllllll}
\hline $\mathrm{n}$ & 1 & 2 & 3 & 4 & 5 & 6 & 7 & 8 & 9 & 10 \\
\hline $\mathrm{R} . \mathrm{I}$. & 0.00 & 0.00 & 0.58 & 0.89 & 1.12 & 1.26 & 1.36 & 1.41 & 1.46 & 1.49 \\
\hline
\end{tabular}

According to the above-mentioned Evaluation Index System of University WeChat Public Platform (see Table 1), this study invites 8 experts specializing in the field of university WeChat public platform to participate in the interview and the evaluation of indexes. The mean value of each index obtained from the eight experts is calculated, leading to the following judgment matrices ( see Table 3 7).

Table 3. Level 1 Evaluation Index Judgment Matrix of University WeChat Public Platform

\begin{tabular}{cccccc}
\hline Index & Platform Design & Platform Function & Platform Content & Others & Weight \\
\hline Platform Design & 1.0000 & 1.1500 & 0.7125 & 1.7333 & 0.2553 \\
Platform Function & 0.8696 & 1.0000 & 1.3167 & 2.8750 & 0.3150 \\
Platform Content & 1.4035 & 0.7595 & 1.0000 & 2.8750 & 0.3094 \\
Others & 0.5769 & 0.3478 & 0.3478 & 1.0000 & 0.1202 \\
\hline
\end{tabular}

$$
\lambda_{\max }=4.0683, C I=0.0228, C R=0.0256<0.1 \text {. }
$$

Table 4. Level 2 Index "Platform Design” Judgment Matrix

\begin{tabular}{ccccc}
\hline Index & Friendliness & Simplicity & Aesthetics & Weight \\
\hline Friendliness & 1.0000 & 2.5000 & 2.7917 & 0.5526 \\
Simplicity & 0.4000 & 1.0000 & 2.8750 & 0.3030 \\
Aesthetics & 0.3582 & 0.3478 & 1.0000 & 0.1444 \\
\hline
\end{tabular}

$\lambda_{\max }=3.1001, \quad C I=0.0501, C R=0.0864<0.1$.

Table 5. Level 2 Index "Platform Function" Judgment Matrix

\begin{tabular}{ccccc}
\hline Index & $\begin{array}{c}\text { Consultation and } \\
\text { Interaction }\end{array}$ & $\begin{array}{c}\text { Self-service } \\
\text { Information }\end{array}$ & $\begin{array}{c}\text { Notification } \\
\text { Push }\end{array}$ & Weight \\
\hline Consultation and Interaction & 1.0000 & 0.8833 & 0.8000 & 0.2954 \\
Self-service Information & 1.1321 & 1.0000 & 1.2917 & 0.3765 \\
Notification Push & 1.2500 & 0.7742 & 1.0000 & 0.3281 \\
\hline
\end{tabular}

$\lambda_{\max }=3.0139, \quad C I=0.0070, C R=0.0120<0.1$. 
Table 6. Level 2 Index "Platform Content" Judgment Matrix

\begin{tabular}{ccccccc}
\hline Index & Richness & Timeliness & Practicality & Authority & Personalization & Weight \\
\hline Richness & 1.0000 & 0.8167 & 0.8824 & 0.7722 & 1.9729 & 0.1839 \\
Timeliness & 1.2244 & 1.0000 & 1.9000 & 1.4167 & 3.7500 & 0.2984 \\
Practicality & 1.1333 & 0.5263 & 1.0000 & 1.6639 & 4.0000 & 0.2377 \\
Authority & 1.2950 & 0.7059 & 0.6010 & 1.0000 & 3.9167 & 0.2103 \\
Personalization & 0.5069 & 0.2667 & 0.2500 & 0.2553 & 1.0000 & 0.0697 \\
\hline
\end{tabular}

$\lambda_{\max }=5.1270, \quad C I=0.0318, C R=0.0283<0.1$.

Table 7. Level 2 "Others” Judgment Matrix

\begin{tabular}{ccccc}
\hline Index & Security & Feedback & Accessibility & Weight \\
\hline Security & 1.0000 & 5.15625 & 3.4167 & 0.6767 \\
Feedback & 0.1939 & 1.0000 & 0.9896 & 0.1500 \\
Accessibility & 0.2927 & 1.0105 & 1.0000 & 0.1733 \\
\hline$\lambda_{\max }=3.0178, \quad C I=0.0089, C R=0.0153<0.1$. & &
\end{tabular}

From Tables 3-7 above, all the CR values are less than 0.1, which shows that the judgment matrix of each level has satisfactory consistency and that the weights are not logically wrong. The weight distribution of the Evaluation Index System of University WeChat Public Platform is thus obtained by analyzing the quantitative statistics of AHP (see Fig. 1):

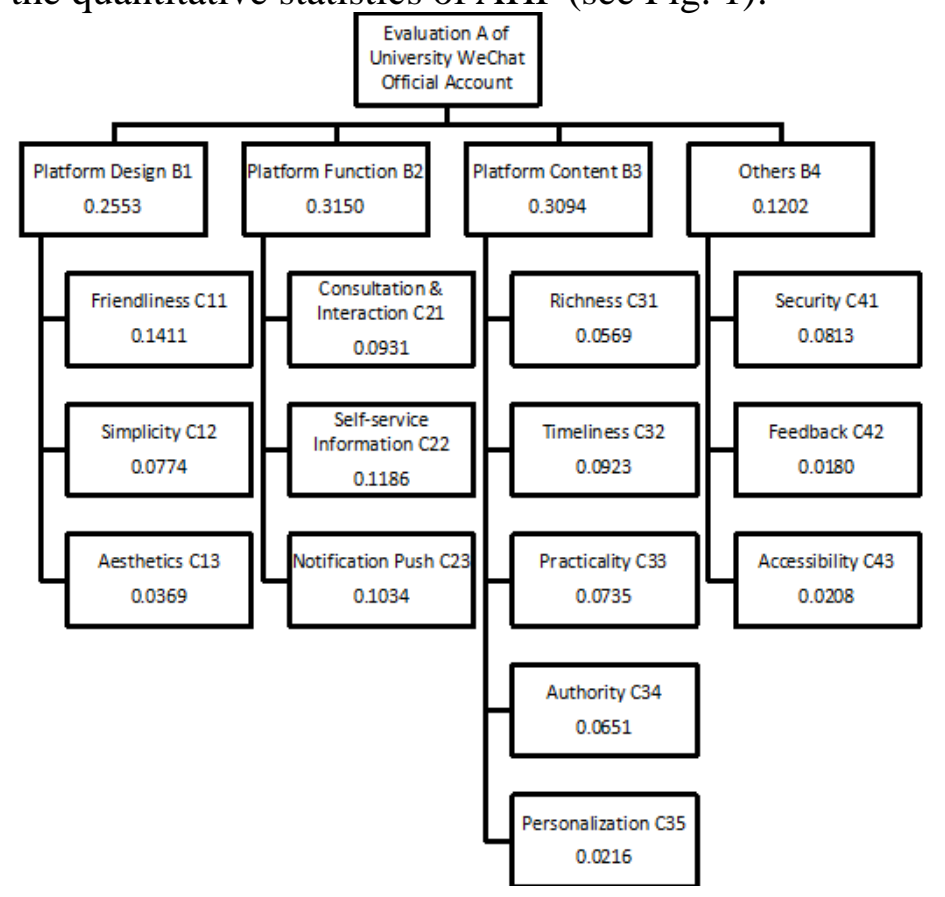

Fig. 1. Evaluation Model of University WeChat Public Platform

In this study, the characteristics and user experience of the WeChat public platform in colleges and universities are reviewed, and the Evaluation Model of University WeChat Public Platform is constructed with the adoption of AHP. Overall, the model and the weight distribution correspond to the actual situation of the WeChat public platform service in universities, which suggests that the model established in this paper is effective and reliable. In particular, the construction of WeChat public platforms in universities emphasizes Platform Function and Platform Content that take up a larger proportion, followed by the other two aspects, Platform Design and Others. As far as Platform Function is concerned, the subscribers pay more attention to Self-service Information, followed by Notification Push and Consultation \& Interaction; When it comes to Platform Content, subscribers care more about Timeliness and Practicality; As for Platform Design, Friendliness is the most emphasized feature, followed by Simplicity and Aesthetics; In Others, Security has the greatest weight. 


\section{An Example of the Evaluation Index System of University WeChat Public Platform: Xiamen University of Technology}

On the basis of the above-mentioned Evaluation Index System (see Fig. 1), the Evaluation Questionnaire of Xiamen University of Technology WeChat Public Platform is designed, which uses plain and comprehensible language to allow subscribers to complete the evaluation of the 14 Level 2 Indexes. The Likert Scale is used for index scoring and the measurements are based on five ordered responses levels: "strongly disagree", "disagree", "neither disagree nor agree", "agree", "strongly agree". What's more, there are transitional responses for specific questions from "not rich at all" to "very rich", "impractical at all" to "very practical" and "not authoritative at all" to "very authoritative". It is an ordinal scale with 1, 2, 3, 4 and 5 points for each response level respectively. Through the Internet and WeChat, 128 questionnaires were distributed to subscribers of Xiamen University of Technology WeChat Public Platform, all of which were valid. The final evaluation results are shown in Table 8.

Table 8. Evaluation Results of Xiamen University of Technology WeChat Public Platform

\begin{tabular}{|c|c|c|c|c|c|}
\hline & Evaluation Index & Synthetic Weight $w_{i}^{\prime}$ & Grade $S_{i}$ & Score & Total Score \\
\hline $\begin{array}{l}\text { Platform } \\
\text { Design }\end{array}$ & $\begin{array}{l}\text { Friendliness } \\
\text { Simplicity } \\
\text { Aesthetics }\end{array}$ & $\begin{array}{l}0.1411 \\
0.0774 \\
0.0369\end{array}$ & $\begin{array}{c}3.295 \\
3.41 \\
3.51\end{array}$ & $\begin{array}{l}0.4649 \\
0.2639 \\
0.1295\end{array}$ & 0.8583 \\
\hline $\begin{array}{l}\text { Platform } \\
\text { Function }\end{array}$ & $\begin{array}{c}\text { Consultation and } \\
\text { Interaction } \\
\text { Self-service Information } \\
\text { Notification Push }\end{array}$ & $\begin{array}{l}0.0931 \\
0.1186 \\
0.1034 \\
\end{array}$ & $\begin{array}{l}3.225 \\
3.71 \\
3.56 \\
\end{array}$ & $\begin{array}{l}0.3002 \\
0.4400 \\
0.3681\end{array}$ & 1.1083 \\
\hline $\begin{array}{l}\text { Platform } \\
\text { Content }\end{array}$ & $\begin{array}{c}\text { Richness } \\
\text { Timeliness } \\
\text { Practicality } \\
\text { Authority } \\
\text { Personalization }\end{array}$ & $\begin{array}{l}0.0569 \\
0.0923 \\
0.0735 \\
0.0651 \\
0.0216\end{array}$ & $\begin{array}{l}3.41 \\
3.51 \\
3.46 \\
3.85 \\
3.38 \\
\end{array}$ & $\begin{array}{l}0.1940 \\
0.3240 \\
0.2543 \\
0.2506 \\
0.0730\end{array}$ & 1.0959 \\
\hline Others & $\begin{array}{c}\text { Security } \\
\text { Feedback } \\
\text { Accessibility } \\
\end{array}$ & $\begin{array}{l}0.0813 \\
0.0180 \\
0.0208 \\
\end{array}$ & $\begin{array}{l}3.56 \\
3.62 \\
3.41 \\
\end{array}$ & $\begin{array}{l}0.2894 \\
0.0652 \\
0.0709 \\
\end{array}$ & 0.4255 \\
\hline Total & & & & 3.4880 & 3.4880 \\
\hline
\end{tabular}

In terms of Platform Design, as is shown in the table above, the Xiamen University of Technology WeChat Public Platform is rated highly aesthetically, followed by Simplicity, but the score of Friendliness with a higher weight is lower than that of Aesthetics and Simplicity. The Xiamen University of Technology WeChat Public Platform should enhance the friendliness of the platform design. The Flat Design, the core meaning of which is the removal of redundant, heavy and complex decorative effects, has become the mainstream trend in the design of mobile software. The Xiamen University of Technology WeChat Public Platform can try the Flat Design to enhance the friendliness, which creates visual and mental pleasure for subscribers.

As for Platform Function, Self-service Information is gaining more recognition among subscribers, with the highest score, followed by Notification Push and Consultation \& Interaction. That is why Consultation \& Interaction should be paid more attention to during the construction. Only by strengthening Consultation \& Interaction can the "stickiness" between subscribers and the official account be fully enhanced. Indeed, the two important features of Timeliness and Interaction are what distinguish WeChat Public Platforms from the traditional media, so specialized personnel should be arranged in the back-end management in order to have timely communication with subscribers, and answer all questions in a quick and efficient manner. Meanwhile, their communication should be polite and standardized in a kind and amiable tone, rather than an impatient, sarcastic and indifferent one.

For Platform Content, Richness and Personalization are rated lower compared with Timeliness, Authority and Practicality. The Xiamen University of Technology WeChat Public Platform should enhance its richness and personalization of spreading information, because the content, quality and 
richness of the information exert a great impact on the reading experience of subscribers. Consequently, the platform, making the most of diverse and interesting texts, images, audio, video and other forms, should carefully collect and edit the tweets to appeal to subscribers. At the same time, it is necessary to collect information in many ways and fully grasp the needs of different subscribers. Only when the corresponding modules are increased and the function dimensions are expanded can the Xiamen University of Technology WeChat Public Platform meet the different interests and needs of different subscribers and its perfornalization can be greatly enhanced.

In Others, Security with the highest weight also scores the highest, but the platform should be strengthened in terms of protecting subscribers' privacy.

\section{Conclusion}

With the rapid development of the Internet, the WeChat public platforms in colleges and universities have become the main channel for college students, society and enterprises to obtain information. It is also the main position of information publicity and ideological education. Therefore, it is of crucial significance for college management in the new era to evaluate the service quality of WeChat public platforms and to build the new media platform. On the basis of empirical research, this paper constructs the Evaluation Index System of University WeChat Public Platform, and uses the Analytic Hierarchy Process, combined with expert interview and questionnaire, to build the Evaluation Model of University WeChat Public Platform. Furthermore, the Xiamen University of Technology WeChat Public Platform serves as an example and the application and analysis of this Evaluation Model provide suggestions, references and guidance for further improvement of service.

However, there are also some limitations in this research, i.e. due to the strong subjectivity, the establishment of the Index System and the application of AHP are inevitably influenced by human factors. In addition, the samples of this survey could not cover all subscribers of the WeChat official accounts in colleges and universities.

\section{References}

[1] D. Yu. Review of research on WeChat public accounts in Colleges and universities . News Research Guide, vol.8,no.5,pp.19-20+50,2017.

[2] AI-Khalifa H S. A framework for evaluating university mobile websites. Online Information Review, vol.38,no.2,pp.166-185,2014.

[3] T. Lu , X. Lei. Evaluation and empirical research on network information service quality. Library and Information Knowledge, no.1, 2008.

[4] X. Guo. Research on government WeChat public platform information service and quality and its evaluation [D]. Anhui: Anhui University, 2016.

[5] B. Zhang . AHP and its application case [M]. Beijing: Publishing House of Electronics Industry, 2014.1. 